\title{
The way to early childhood education equity - policies to tackle the urban-rural disparities in China
}

\author{
Xiumin Hong ${ }^{1 *}$, Peng Liu', Qun Ma ${ }^{1}$ and Xin Luo ${ }^{2}$
}

\footnotetext{
* Correspondence: xiuminhong@bnu.edu.cn

${ }^{1}$ Faculty of Education, Beijing Normal University, No. 19,

XinJieKouWai St., HaiDian District, Beijing, China

Full list of author information is available at the end of the article
}

\begin{abstract}
Protecting children's development rights and promoting social equity are the priority and core tasks of the Chinese government and international community. Currently, the inequity of early childhood education (ECE) in China is still severe. The disparities between urban and rural areas are the main contributors to this situation, which are manifested in ECE opportunities, process, and outcome. This research tries to address the inequity issue and evaluate the policies the Chinese government has taken to tackle the inequity. With a policy analysis approach, the research analyzed the official data, documents, policy papers, and laws in order to construct a clear picture of Chinese ECE disparities and the achievement and challenges of the relevant ECE policies. In this article, the background of the urban and rural ECE disparities will be first introduced, followed by the detailed analysis of the disparities in ECE opportunities, process, and outcome. Then the article will describe and analyze the official measures and policies that are employed to tackle the ECE disparities, including the institutional foundations for rural ECE development, optimized allocation of ECE resources, improved rural kindergarten teachers' qualification system, enhanced ECE funding system, and strengthened supervision and evaluation system. The article will also evaluate the effectiveness of the policies and give the implications that can help the further ECE policy-making process.

Keywords: Early childhood education; Early childhood education equity; Urban-rural disparities; Education policy
\end{abstract}

\section{Background}

Equitable educational opportunities, educational process, and educational outcome are the three indicators of education equity (Castelli et al. 2012). Nowadays, early childhood education (ECE) has been prioritized in education policies around the world. In many developed countries, ECE policy has been integrated into anti-poverty or education equity measures (Organization for Economic Co-operation and Development OECD 2013). Before 2010, the Chinese government mainly focused on ECE in urban areas, while in rural areas, ECE had long been neglected (Hu and Roberts 2013). As a result, the current urban-rural disparities of ECE are remarkable in China, and the education inequity is aggravating. In China, urban areas refer to administrative regions with population density above 1,500 people $/ \mathrm{km}^{2}$, whose administration system usually includes municipal government, district government, and town government. Rural areas are regions that include

\section{Springer}


market towns and villages, whose population is less than 3,000 (National Bureau of Statistics of the People's Republic of China 2010). During the past decades, while China has seen dramatic changes in its social and economic landscape, its rural areas developed relatively slowly than its urban counter parts and also received less funding and attention in its ECE sector. The implementation of the Tenth Five-Year Plan of People's Republic of China National Economic and Social Development (2006-2010) has enhanced Chinese ECE development and the issue of ECE equity had aroused widespread social and academic attention. In 2010, the Central Government of China distributed the Chinese Midand Long-term Education Reform and Development Plan (2010-2020), in which education equity was listed as a basic of national education policy. It also marked the beginning of official intervention of ECE inequity in China. Since then, Chinese authorities have implemented a series of measures to promote education equity in ECE, especially focusing on the rural areas, in order to achieve the strategic target of 'rejuvenating China through science and education' (The State Council of the People's Republic of China 1995).

\section{Literature review}

Education has been a basic human right today, and the equity of education has received worldwide attention. Educational equity requires all the citizens to have the equal access to quality education, which is based on principles of fairness and inclusiveness (OECD 2008). In the global level, many countries nowadays are expanding the educational opportunities for their citizens (OECD 2014). However, it should be noted that the notion of educational equity can be quite elusive as a result of the economic, political, and cultural differences among different countries (Levin 2003). The equity issue is particularly prominent in the ECE sector. UNESCO (2008) indicated that many governments failed to tackle the increasing inequality in young children's education caused by different family income, races, regions, etc. In many developing countries, regional gap of ECE, especially the gap between the urban and rural areas, was still enlarging. In Hungary, for example, government had challenge to guarantee the equity in the quality of early years' service in rural area (OECD 2006). Brazil was also troubled by equity issues in ECE among urban disadvantage children and rural children in general (Young 2002). From 1993 to 2009, despite the decline in education gap between the urban and rural areas in India, the Gini index remained above 50\%, which negatively influenced the further act to narrow the urban-rural educational gap (Agrawal 2014). In China, the access of early years' education is still low in rural area, which is not compatible with the economic and social development (Liu 2010). Specifically, in rural area, the teacher-child ratio is considerably lower in rural areas compared with urban area. The rural kindergartens always have oversized groups and their teachers are not fully qualified (Zhang and Yu 2009). For some poverty-stricken areas in China, children also suffer from malnutrition, which can result in the poor literacy performance (Hannum et al. 2014). In order to tackle the inequity issues, many countries have conducted research and taken measures to ensure a good start for the youngest. In Bangladesh, researchers proved that the improvement in the quality of rural preschools could predict higher performance when their children went to primary schools (Aboud and Hossain 2011). In Mexico, early years' service in rural and indigenous areas were evaluated and assessed by the Centre of Investigations and Top Studies in Social Anthropology (CIESAS), chartered by the Mexican Ministry of Education (OECD 2012). In China's Gansu Province, one of the 
least developed regions in China, the rural ECE reform verified the necessities of national financial support for rural ECE (Brock 2009). Shandong Province initiated and strengthened the cooperation between local government and other social entities to ensure the sources of finance for rural ECE. Starting from the county central preschools, the ECE structural reform in Shandong improved the quality of ECE in rural area (Yang et al. 2011). It can be seen that in many developing countries, governments should develop the rural ECE by necessary policy and financial support.

\section{Methods}

\section{Research questions}

This article will explore the following questions: What are the major gaps between urban and rural ECE development in China? What measures and steps have the Chinese government taken to bridge these gaps? What are the further implications for future policies and practices?

\section{Analysis method}

The specific analysis methods are as follows:

(1) The article begins by analyzing the statistics of 2006 to 2012 Chinese urban and rural ECE to clarify the major gaps between urban and rural ECE development. In an effort to objectively reflect the urban-rural disparities of ECE in China, the data for further calculation and analysis are from China Population \& Employment Statistical Yearbook and China Education Statistical Yearbook, which were published by Chinese official agencies - Chinese official websites of Ministry of Education and National Bureau of Statistics. All tables consisted of annual statistics and corresponding ratio calculation. The data are presented in the following three parts: ECE opportunities, ECE process, and ECE results. The disparities of educational opportunities are measured by the number of kindergartens, the number of children in kindergartens, and enrollment rates. The disparities of educational process are measured by teachers' allocation, qualification, professional titles, and kindergarten conditions, including floor space, recreational space, outdoor space, and books. Finally, the disparities of educational results are mainly reflected by the proportion of children who have completed kindergarten.

(2)Based on the problems identified, the corresponding policy initiatives will be analyzed, including the measures to promote ECE equity in China, from aspects of institutional foundation, financial investment, kindergarten system, teacher qualification and compensation mechanism, and evaluation system. This part is based on related policies enacted by the central and local governments, including laws, regulations, rules, policies and educational planning, government work report, leadership speech, government's annual education priorities, and government field research reports, as well as news and commentary released by authoritative media.

(3) Based on the problems and measures, the article will finally analyze the challenges and prospects of rural ECE in China, including rural public-oriented (which are public funded kindergartens in China that provide affordable ECE service to families) ECE resources, cost-sharing and operation-supporting system, teacher training system and teacher's right protection, quality supervision, and evaluation system. 


\section{Results and discussion}

The major urban-rural disparities of ECE in China

In China, the ECE urban-rural inequity is mainly manifested in the following three aspects: opportunities, process, and results. Rural children do not have the same educational opportunities as their urban counterparts. Meanwhile, the educational resources possessed by rural children, including teachers, school buildings, teaching aids, are far less than urban children. Inequitable educational opportunities and process eventually led to inequitable outcomes. In China, compared with its development in urban area, the quality of rural ECE in China has lagged behind. Currently, the urban-rural disparities of Chinese ECE development are severe.

Inequitable opportunities: the exacerbating imbalance of the right to access to ECE between urban and rural areas

The equal opportunities are the basis of the equal ECE process and result. In China, the increasing urban-rural imbalance of the access to ECE has become the bottleneck of equitable educational opportunities.

The widening gap of the number of kindergartens between urban and rural areas

China is largely an agricultural country, in which rural population constitutes the majority of the whole population. Rural children accounted for two thirds of the total number of children. However, the quantity and quality of rural kindergartens cannot meet the needs of rural children because of scattered rural residence and small-scale kindergartens, which are mostly part of local primary schools. With the advancement of urban-rural economic integration and new rural construction during these years, rural infrastructure and public services have been updated, but the 'kindergarten crunch' issue still cannot be solved. Due to the lack of public-oriented kindergarten, most of the kindergartens catering to children in rural areas are illegal as they are unlicensed and are out of government's accreditation and management system. Also, these kindergartens are usually with large children-teacher ratio and low quality. To some extent, these kindergartens have eased the tension of the lack of ECE services in rural areas, but during 2006 to 2012, the number of rural kindergartens was still less than half of the total number of national kindergartens (see Table 1). During this time, the urban-rural gap has further expanded. In 2006, the difference of the proportion of the number of urban and rural kindergartens was only $0.80 \%$; however, in 2012, the figure jumped to $30.58 \%$. The needs of rural children to go to kindergartens are urgent whereas the number of rural kindergartens is still insufficient, which declines a large number of rural children's access to basic ECE service.

\section{The increasing gap between the number of children in urban and rural kindergartens}

From 2006 to 2012, the proportion of urban children in kindergartens experienced a steady upward trend, while that of rural area showed a gradually downward trend. The year 2011 was an exceptionally key year; the proportion of children in urban kindergartens surged from $59.22 \%$ in 2010 to $71.79 \%$ in 2012, whereas the figure in rural areas plunged to $28.21 \%$ in 2012 from $40.78 \%$ in 2010 . Since 2006 , the ratio of the number of children in kindergartens between the urban and rural areas has been enlarging year by year, especially from 2010 to 2011 , sharply rising from $18.44 \%$ in 2010 to $41.96 \%$ in 2011 . The data 
Table 1 The number of urban and rural kindergartens, 2006 to 2012

\begin{tabular}{lllllll}
\hline Year & Nation & \multicolumn{2}{l}{ Urban areas } & & & \multicolumn{2}{l}{ Rural areas } \\
& & Total & Percent & & Total & Percent \\
\hline 2006 & 130,495 & 65,776 & 50.40 & & 64,719 & 49.60 \\
2007 & 129,086 & 67,743 & 52.48 & & 61,343 & 47.52 \\
2008 & 133,722 & 69,419 & 51.91 & & 64,303 & 48.09 \\
2009 & 138,209 & 71,843 & 51.98 & & 66,366 & 48.02 \\
2010 & 150,420 & 78,832 & 52.41 & & 71,588 & 47.59 \\
2011 & 166,750 & 108,066 & 64.81 & & 58,684 & 35.19 \\
2012 & 181,251 & 118,160 & 65.19 & 63,091 & 34.81 \\
\hline
\end{tabular}

reflects that the urban-rural disparity of ECE access has been increasingly significant (see Table 2).

The disparity between the urban and rural kindergarten enrollment rate

Gross kindergarten enrollment rate is an important indicator of the equity of ECE opportunities. Table 3 shows that the gap of Chinese kindergarten gross enrollment rate between urban and rural areas is widening. In 2006, the 3-year ECE gross enrollment rate was $58.05 \%$ and $29.63 \%$ in urban and rural areas, respectively, with a difference about $28 \%$. In 2010, the gap expanded to nearly $35 \%$. After only 1 year, the disparity in 2011 increased to 59\%. In addition, the disparity of 1-year ECE gross enrollment rate enlarged from $21.94 \%$ in 2006 to $27.56 \%$ in 2010. By 2011, the figure increased by approximately $22 \%$ and jumped to $49.53 \%$ (see Table 3 ).

Inequitable process: the gap of the distribution of public-oriented early childhood educational resources between urban and rural areas

Equitable allocation of public-oriented early childhood educational resources is not only the key for children to enjoy the same public-oriented resources but is also the guarantee for children to achieve equal ECE process and receive the equitable educational services. Public-oriented early childhood educational resources include human and material. To be specific, teachers are the major human resource, and the quality of human resources in ECE is mainly measured by the teacher-children ratio, the structure of teachers' qualification, and professional development. Material resources consist of kindergarten indoor space, recreational space, outdoor space, and books.

Table 2 The number of urban and rural children in kindergartens, 2006 to 2012 (Unit: in person, \%)

\begin{tabular}{lllllll}
\hline Year & \multirow{2}{*}{$\begin{array}{l}\text { National } \\
\text { level }\end{array}$} & \multicolumn{2}{l}{ Urban areas } & & \multicolumn{2}{l}{ Rural areas } \\
& Total & & Percent & & Total & Percent \\
\hline 2006 & $22,638,509$ & $12,160,090$ & 53.71 & & $10,478,419$ & 46.29 \\
2007 & $23,488,300$ & $13,157,106$ & 56.02 & & $10,331,194$ & 43.98 \\
2008 & $24,749,600$ & $14,076,041$ & 56.87 & & $10,673,559$ & 43.13 \\
2009 & $26,578,141$ & $15,318,161$ & 57.63 & & $11,259,980$ & 42.37 \\
2010 & $29,766,695$ & $17,626,405$ & 59.22 & & $12,140,290$ & 40.78 \\
2011 & $34,244,456$ & $24,306,519$ & 70.98 & & $9,937,937$ & 29.02 \\
2012 & $36,857,624$ & $26,459,845$ & 71.79 & & $10,397,779$ & 28.21 \\
\hline
\end{tabular}


Table 3 The gross enrollment rate (GER) of urban and rural kindergartens, 2006 to 2012 (\%)

\begin{tabular}{|c|c|c|c|c|c|c|}
\hline \multirow[t]{2}{*}{ Year } & \multicolumn{3}{|c|}{ Three-year GER } & \multicolumn{3}{|l|}{ One-year GER } \\
\hline & Urban areas & Rural areas & Disparity & Urban areas & Rural areas & Disparity \\
\hline 2006 & 58.05 & 29.63 & 28.42 & 72.08 & 50.14 & 21.94 \\
\hline 2007 & 62.11 & 29.86 & 32.25 & 74.85 & 49.51 & 25.34 \\
\hline 2008 & 65.63 & 31.73 & 33.90 & 78.96 & 50.78 & 28.18 \\
\hline 2009 & 67.72 & 33.13 & 34.59 & 77.05 & 49.03 & 28.02 \\
\hline 2010 & 69.76 & 34.95 & 34.81 & 75.68 & 48.12 & 27.56 \\
\hline 2011 & 87.72 & 28.59 & 59.13 & 76.37 & 29.64 & 46.73 \\
\hline 2012 & 89.10 & 29.69 & 59.42 & 81.24 & 31.70 & 49.53 \\
\hline
\end{tabular}

The notable differences of the number of kindergarten teachers and the teacher-children ratio between urban and rural areas

Appropriate teacher-children ratio is the key to improve teacher-children interaction and the guarantee of the education quality. At present, rural kindergarten teachers in China are still in a so-called 'three lows' situation - low social status, low wages, and low public welfare. Besides, there is a lack of effective incentives system to attract and keep qualified teachers. As a result, rural kindergartens are confronted with a severe loss of qualified teachers. As can be seen in Table 4, teachers are very scarce in rural areas. Although there was a steady upward trend of the number of teachers from 2006 to 2010, it experienced fluctuations in 2011 and 2012. There is still a large gap between the number of urban kindergarten teachers and the number of rural kindergarten teachers. From 2006 to 2012, the number of kindergarten teachers in urban areas is 3.09 to 5.52 times higher than as the number in rural areas (see Table 4). Besides, in rural kindergartens, the average number of teachers per class is less than one person, far below the national average and urban level. During this period of time, the urban teacher-children ratio and the average number of teachers per class are two to three times higher than those in rural areas.

The gap of teachers' qualification between urban and rural kindergarten teachers

The differences between urban and rural kindergarten teachers are significant not only on the quantity but also on the quality which is reflected in teachers' professionalism and the level of qualification. For a long time, China has only focused on teachers' professional training for compulsory education and tertiary education, while it has ignored the qualification and professional development for kindergarten teachers. Compared

Table 4 Urban and rural kindergarten teachers' allocation, 2006 to 2012 (in person)

\begin{tabular}{|c|c|c|c|c|c|c|}
\hline \multirow[t]{2}{*}{ Year } & \multicolumn{2}{|c|}{ Kindergarten teachers } & \multicolumn{2}{|c|}{ Teacher-children ratio } & \multicolumn{2}{|c|}{ Average number of teachers per class } \\
\hline & Urban areas & Rural areas & Urban areas & Rural areas & Urban areas & Rural areas \\
\hline 2006 & 586,558 & 189,933 & $1 / 21$ & $1 / 55$ & 1.49 & 0.48 \\
\hline 2007 & 636,716 & 190,049 & $1 / 21$ & $1 / 54$ & 1.51 & 0.50 \\
\hline 2008 & 689,954 & 208,598 & $1 / 21$ & $1 / 51$ & 1.55 & 0.55 \\
\hline 2009 & 753,456 & 232,433 & $1 / 20$ & $1 / 49$ & 1.57 & 0.60 \\
\hline 2010 & 868,379 & 275,846 & $1 / 20$ & $1 / 44$ & 1.57 & 0.66 \\
\hline 2011 & $1,113,913$ & 201,721 & $1 / 22$ & $1 / 49$ & 1.34 & 0.48 \\
\hline 2012 & $1,249,674$ & 229,563 & $1 / 21$ & $1 / 45$ & 1.44 & 0.58 \\
\hline
\end{tabular}


with urban kindergarten teachers' qualifications, the overall level of rural kindergarten teachers' qualifications is low. From 2006 to 2012, more than half of the urban kindergarten teachers graduated from vocational school or above, and the proportion of teachers who had received higher education is increasing (see Table 5). Although the proportion of rural kindergarten teachers with vocational school qualifications and above is increasing in recent years, the figure is still far below than that of the urban area. In fact, the majority of their qualifications are still high school degree (2012: 46\%). Research shows that a large part of rural kindergarten teachers were not majored in ECE in pre-service training and education, which causes a serious mismatch between jobs and qualification. Besides, there is considerable number of kindergarten teachers transferring from primary school who had received little training on ECE. In recent years, the differences of kindergarten teachers with qualified qualifications between the urban area and rural area have been fluctuating between $22.15 \%$ and $26.75 \%$ (the interval of subtracting the number of teachers' qualification in rural areas from that in urban areas). Hence, it is hard to guarantee rural kindergarten teachers' quality.

\section{The dramatic disparities of teachers' professional titles between urban and rural kindergarten} teachers

Professional title refers to the name of a certain position granted by authority, a symbol of status in accordance with professionals' expertise, practical skills, and work performance. In China, there are three main categories of kindergarten teachers' professional titles, which are included in the primary and secondary school teachers' professional titles system. Running from the highest to lowest, they are senior titles (including senior secondary title and senior primary title), intermediate titles (including first grade primary title) and entry-level titles (including second grade primary title and third grade primary title). From 2006 to 2012, a large proportion of Chinese kindergarten teachers did not attend the professional title system. Especially for kindergarten teachers in rural areas, the majority of them were out of the system. Therefore, they lacked the motivation of continuous professional development and could hardly receive in-service training and support. In 2012, 77.53\% of rural kindergarten teachers had no professional titles, with $9 \%$ less compared with urban kindergarten teachers. Meanwhile, the level of professional titles of rural kindergarten teachers was generally low. From 2006 to 2012, the proportion of urban kindergarten teachers with titles of senior primary and senior secondary was seven to eight times higher than rural kindergarten

Table 5 The urban-rural distribution of teachers' qualification above associate bachelor, 2006 to 2012 (\%)

\begin{tabular}{llll}
\hline Year & \multicolumn{2}{l}{ Above associate bachelor } \\
\cline { 2 - 4 } & Urban areas & Rural areas & Disparity \\
\hline 2006 & 57.64 & 30.89 & 26.75 \\
2007 & 59.71 & 33.82 & 25.89 \\
2008 & 62.44 & 36.43 & 26.01 \\
2009 & 64.68 & 38.83 & 25.85 \\
2010 & 66.19 & 41.76 & 24.43 \\
2011 & 66.08 & 42.61 & 23.47 \\
2012 & 68.57 & 46.42 & 22.15 \\
\hline
\end{tabular}


teachers. As for teachers with the titles of first grade primary, second grade primary, and third grade primary, from 2006 to 2010, the ratio in urban areas was four to five times higher than that in rural areas; the figure even reached above seven times by 2011 (see Table 6). This situation largely dampens kindergarten teachers' enthusiasm in rural areas and undermines the job stability of rural kindergarten teachers.

The increasing gap of kindergarten's physical conditions between urban and rural areas Rural ECE in China suffers not only from the substandard 'software', but also the 'hardware'. Overall, the physical conditions of kindergartens in rural areas affect the quality of ECE. Most of the kindergartens in rural China did not meet the national standard. Due to the lack of finance and public attention, for a long time being, rural kindergartens in China suffer from the shortage of physical space, poor condition of buildings, inadequate activity space, obsolete teaching equipment and facilities, the lack of clean toilets and emergency exits, and insufficient toys and books for playing and reading. As can be seen from Table 7, from 2006 to 2011, the disparities between urban and rural kindergarten's physical conditions, including average constructive space per child, average activity space per child, average outdoor space per child and average books per child, were slowly narrowing, but the gaps remained obvious (see Table 7). For the distribution of books, the gap was even enlarging. Therefore, kindergarten conditions and children learning environments in rural China still lag behind urban areas.

Inequitable results: the remaining difference of the proportion of children completing kindergarten between urban and rural area

A lot of empirical evidence shows that ECE can bring significant short-term and longterm benefits to disadvantaged children, which indicates that the long-term benefits of ECE do exist and can be kept up until the elementary school or even longer (Berlinski et al. 2009). According to Table 8, from 2006 to 2012, the proportion of school-age children receiving ECE in rural China was increasing and was steadily approaching to the figure of urban areas. Due to the development of urbanization and 'floating population' (rural population migrating to cities to pursue job opportunities and quality resources), the number of children in urban areas is growing while that in rural areas is decreasing. Nowadays, urban pupils actually consist of the local urban children and children of the floating population. Although the proportion of school-age children receiving ECE in rural China was increasing and steadily approaching to the figure of

Table 6 The proportion of different professional titles of urban-rural kindergarten teachers, 2006 to 2012 (\%)

\begin{tabular}{|c|c|c|c|c|c|c|c|c|c|c|}
\hline \multirow[t]{2}{*}{ Year } & \multicolumn{2}{|c|}{ Senior secondary } & \multicolumn{2}{|c|}{ Senior primary } & \multicolumn{2}{|c|}{$\begin{array}{l}\text { First grade } \\
\text { primary }\end{array}$} & \multicolumn{2}{|c|}{$\begin{array}{l}\text { Second grade } \\
\text { primary }\end{array}$} & \multicolumn{2}{|c|}{$\begin{array}{l}\text { Third grade } \\
\text { primary }\end{array}$} \\
\hline & $\begin{array}{l}\text { Urban } \\
\text { areas }\end{array}$ & $\begin{array}{l}\text { Rural } \\
\text { areas }\end{array}$ & $\begin{array}{l}\text { Urban } \\
\text { areas }\end{array}$ & $\begin{array}{l}\text { Rural } \\
\text { areas }\end{array}$ & $\begin{array}{l}\text { Urban } \\
\text { areas }\end{array}$ & $\begin{array}{l}\text { Rural } \\
\text { areas }\end{array}$ & $\begin{array}{l}\text { Urban } \\
\text { areas }\end{array}$ & $\begin{array}{l}\text { Rural } \\
\text { areas }\end{array}$ & $\begin{array}{l}\text { Urban } \\
\text { areas }\end{array}$ & $\begin{array}{l}\text { Rural } \\
\text { areas }\end{array}$ \\
\hline 2006 & 89.42 & 10.58 & 88.54 & 11.46 & 81.77 & 18.23 & 82.58 & 17.42 & 83.94 & 16.06 \\
\hline 2007 & 87.68 & 12.32 & 87.71 & 12.29 & 82.01 & 17.99 & 83.17 & 16.83 & 83.50 & 16.50 \\
\hline 2008 & 84.20 & 15.80 & 86.22 & 13.78 & 81.87 & 18.13 & 83.96 & 16.04 & 85.03 & 14.97 \\
\hline 2009 & 87.06 & 12.94 & 86.04 & 13.96 & 82.07 & 17.93 & 84.92 & 15.08 & 83.41 & 16.59 \\
\hline 2010 & 87.41 & 12.59 & 84.92 & 15.08 & 81.76 & 18.24 & 84.65 & 15.35 & 83.93 & 16.07 \\
\hline 2011 & 93.34 & 6.66 & 89.88 & 10.12 & 87.55 & 12.45 & 89.45 & 10.55 & 87.68 & 12.32 \\
\hline 2012 & 91.64 & 8.36 & 89.79 & 10.21 & 87.57 & 12.43 & 88.05 & 11.95 & 88.50 & 11.50 \\
\hline
\end{tabular}


Table 7 Kindergarten conditions of urban and rural areas, 2006 to 2011

\begin{tabular}{|c|c|c|c|c|c|c|c|c|c|c|c|c|}
\hline \multirow[t]{2}{*}{ Year } & \multicolumn{3}{|c|}{ Average space per child $\left(\mathrm{m}^{2}\right)$} & \multicolumn{3}{|c|}{ Average activity space per child $\left(\mathrm{m}^{2}\right)$} & \multicolumn{3}{|c|}{ Average outdoor space per child $\left(\mathrm{m}^{2}\right)$} & \multicolumn{3}{|c|}{ Average books per child (in book) } \\
\hline & Urban areas & Rural areas & Disparity & Urban areas & Rural areas & Disparity & Urban areas & Rural areas & Gap & Urban areas & Rural areas & Disparity \\
\hline 2006 & 5.67 & 2.27 & 3.40 & 2.13 & 0.94 & 1.19 & 4.38 & 3.25 & 1.13 & 4.56 & 2.05 & 2.50 \\
\hline 2007 & 5.70 & 2.29 & 3.41 & 2.15 & 0.95 & 1.20 & 4.81 & 2.71 & 2.09 & 4.79 & 2.16 & 2.63 \\
\hline 2008 & 5.78 & 2.44 & 3.33 & 2.18 & 0.99 & 1.19 & 3.75 & 2.82 & 0.93 & 4.90 & 2.36 & 2.54 \\
\hline 2009 & 5.74 & 2.58 & 3.16 & 2.17 & 1.03 & 1.14 & 3.61 & 2.75 & 0.85 & 4.89 & 2.13 & 2.75 \\
\hline 2010 & 5.68 & 2.79 & 2.89 & 2.18 & 1.13 & 1.05 & 3.58 & 3.04 & 0.53 & 4.97 & 2.27 & 2.70 \\
\hline 2011 & 5.11 & 2.60 & 2.51 & 2.06 & 1.13 & 0.93 & 3.03 & 2.68 & 0.35 & 5.14 & 2.41 & 2.72 \\
\hline
\end{tabular}


Table 8 The proportion of urban and rural new pupils receiving ECE, 2006 to 2012 (in person, \%)

\begin{tabular}{|c|c|c|c|c|c|c|}
\hline \multirow{2}{*}{ Year } & \multicolumn{3}{|c|}{ Urban areas } & \multicolumn{3}{|l|}{ Rural areas } \\
\hline & $\begin{array}{l}\text { Primary } \\
\text { school } \\
\text { entrants }\end{array}$ & $\begin{array}{l}\text { Having received ECE } \\
\text { before primary school }\end{array}$ & Percent & $\begin{array}{l}\text { Primary } \\
\text { school } \\
\text { entrants }\end{array}$ & $\begin{array}{l}\text { Having received ECE } \\
\text { before primary school }\end{array}$ & Percent \\
\hline 2006 & $6,479,163$ & $6,022,826$ & 92.96 & $10,814,409$ & $8,630,047$ & 79.80 \\
\hline 2007 & $7,014,286$ & $6,613,139$ & 94.28 & $10,346,386$ & $8,530,154$ & 82.45 \\
\hline 2008 & $7,099,448$ & $6,787,721$ & 95.61 & $9,857,702$ & $8,237,143$ & 83.56 \\
\hline 2009 & $6,957,149$ & $6,665,562$ & 95.81 & $9,420,829$ & $8,065,594$ & 85.61 \\
\hline 2010 & $7,765,504$ & $7,485,197$ & 96.39 & $9,151,503$ & $8,052,509$ & 87.99 \\
\hline 2011 & $10,208,687$ & $9,794,358$ & 95.94 & $7,159,293$ & $6,319,609$ & 88.27 \\
\hline 2012 & $10,574,035$ & $10,327,142$ & 97.67 & $6,572,605$ & $6,048,998$ & 92.03 \\
\hline
\end{tabular}

urban areas, the difference between urban and rural China could not be denied. That is to say, the urban-rural gap still existed, though gradually bridging. In 2012, the disparity between urban and rural areas was the smallest - the proportion of urban and rural primary school new students who had received ECE (including pre-primary class) was 97.67\% and $92.03 \%$ respectively, with a difference about $5 \%$ (see Table 8 ).

The policies and measures to promote ECE equity

Due to the realities of Chinese urban-rural disparities currently, there is still significant inequity concerning urban-rural educational opportunities, educational resources, and teachers' qualification. To address these issues, since 2010, the Chinese government has carried out a variety of policies and has implemented a series of measures. These policies and measures include financial investment, construction of new kindergartens, teachers' professional development, and funding system and supervision. The government's efforts aimed at promoting the development of ECE in rural areas and bridging the urban-rural gap.

\section{Implementation of multiple policies to lay the institutional foundation for rural ECE} development

Educational equity can contribute to individuals' development in a country and is the cornerstone of social equity (OECD 2011a). In order to realize the national strategy of building a harmonious society, the Chinese government puts educational equity as a core of educational policy. As the start of Chinese education system, ECE equity policy is in the cores of Chinese ECE policies. In China, the educational inequity is caused by a wide range of factors. To solve the problem, policies are needed both inside and outside the education system and should be combined to be effective (Levin 2003). Since 2010, the Chinese government has implemented multiple policies and measures to promote the development of rural ECE, which has laid the foundation for the equitable ECE development.

In 2010, promoting educational equity was listed as Chinese basic education policy in Chinese Mid- and Long-term Education Reform and Development Plan (2010-2020). The document proposed the development tasks and targets of Chinese education during the period of 2010 to 2020, which provided the guidelines of recent Chinese education policymaking. In the Plan, two of the three ECE development tasks were 
associated with enhancing ECE in rural areas and promoting educational equity, which reflected the determination of the Chinese government to combat ECE inequity.

Under the guidance of the Plan, the Chinese government distributed the State Council: Opinion Concerning Current Development of Early Childhood Education in 2010, which detailed the specific measures of ECE development. The Opinion also brought forward a variety of guiding suggestions to promote rural ECE, including balancing educational resources, increasing financial investment, enhancing the quality of kindergarten teachers' qualification and establishing Promoting Rural Early Childhood Education Project. Meanwhile, the Opinion proposed to launch Early Childhood Education Three-Year Action Plan. According to this Plan, every province in China should analyze the local ECE development and establish realistic goals and actions which reflect the local realities and area characteristics. In 2011, local governments in China have all developed their local Early Childhood Education Three-Year Action Plan. By 2013, the first Three-Year Action Plan has made impressive achievements (the data will be presented in the following text); currently, the second Three-Year Action Plan is about to start.

In addition to the three major policies discussed above, the Ministry of Education and Ministry of Finance jointly distributed Ministry of Finance, Ministry of Education: The Notice on Increasing Financial Investment to Support the Development of Early Childhood Education. It proposed seven major projects in four categories to promote early childhood educational equity. These include 'kindergarten reconstruction' category (including 'Converting Idle Rural Schools into Kindergartens Project', 'Building Kindergartens Affiliated To Local Rural Primary Schools Project', and 'Mobile Rural Early Childhood Education-Supporting Sites Project'), 'grants and subsidies' category (including 'Supporting Public-oriented', 'Encouraging Establishment of Urban Kindergartens Through Various Approaches and Solving Migrant Children's Kindergarten Crunch'), 'kindergarten teacher training' category (implementing 'National Kindergarten Teacher Training Project'), and 'early childhood education funding' category (establishing ECE funding system).

From the Chinese Mid- and Long-term Education Reform and Development Plan to local Early Childhood Education Three-Year Action Plan, and then to the collaboration of different ministries, a series of policies have provided institutional guarantee and have laid the foundation for Chinese rural ECE development.

\section{Increase of financial investment to balance the allocation of urban-rural educational} resources

Nowadays, it is widely accepted that education is an important engine for economic growth (Chapman and Lounkaew 2013). From the point of economics, it is wiser to invest in ECE than invest in later educational stages (Heckman 2011). Another study shows that in developing countries, in order to narrow the gap between urban and rural disadvantaged children, the government's financial investment and funding is essential (Lounkaew 2013). However, in China, ECE expenditure only accounted for about $1.3 \%$ of the public education expenditure during the past years (Hong and Pang 2009). Moreover, the limited expenditure is more accessible in urban areas than in rural areas; the 'Matthew Effect' has further exacerbated the urban-rural disparities of Chinese ECE. Therefore, as a developing country committing to promoting educational equity, China is bound to provide strong financial support to ECE, especially in rural areas. 
In the State Council: Opinion Concerning Current Development of Early Childhood Education, the Chinese government proposed policies like 'local governments should arrange special funding, focusing on supporting rural kindergarten' and 'the central government set up special funding to support the early childhood education and bilingual education of central and western rural areas, ethnic minority areas, and border areas. Local governments need to increase investment, focusing on promoting early childhood education of remote areas and ethnic minority areas' (The State Council of the People's Republic of China 2010b).

To implement the Opinion and achieve the purpose of meeting the financial needs of ECE in rural areas in 2010, the Ministry of Education and the National Development and Reform Commission jointly launched the 'Pilot Scheme of Rural Early Childhood Education Promotion Project'. The project provides special funding to support the establishment of rural public and public-oriented kindergartens in central and western provinces. The project aims at offering basic and quality rural ECE service to eligible children in subsidized areas. Thus, a reasonable public ECE service system covering both urban and rural areas is set up thanks to the efforts of the central government and local authorities. According to the statistics, a special investment of 5.6 billion RMB has been invested, and 3,163 kindergartens have been reconstructed. In total, 25 provinces has benefited from the project during 2010 to 2012 (Ministry of Education of the People's Republic of China 2012).

Additionally, detailed funding standards are proposed in the Ministry of Finance, Ministry of Education: The Notice on Increasing Financial Investment to Support the Development of Early Childhood Education. In Converting Idle Rural School into Kindergartens Project, central finance offers subsidies according to local realities of the regions. To be specific, the central government pays $80 \%$ and $60 \%$ of expenditures in western and central China, respectively. As for undeveloped areas in eastern China, the central government will decide the proportion of subsidy by the local situation of every province. In Building Kindergartens Affiliated to Local Rural Primary Schools Project, the central government provides a onetime subsidy of 50,000RMB for every class of kindergarten. For Mobile Rural Early Childhood Education-Supporting Sites Project, there is a one-time subsidy of 15,000RMB for every newly established education-supporting site. In terms of volunteer's allowance, every volunteer in the western area, central area, and eastern area can receive 15,000RMB, 10,000RMB, and 5,000RMB every year, respectively.

\section{Establishment of rural kindergartens through various approaches and improvement of educational opportunities for rural children}

In 2003, the State Council promulgated the Guiding Opinions on the Reform and Development of Early Childhood Education which proposed that the long-term Chinese kindergarten 1-year gross enrollment rate should reach $80 \%$; as for the undeveloped area, the rate should reach $60 \%$ by 2007 (The State Council of the People's Republic of China 2003). However, according to statistics, in rural areas, kindergarten 1-year gross enrollment rate was only $47.42 \%$ by 2007 (Hong and Luo 2012), 10\% less than the proposed goal. Analyzing the data, it can be seen that in 2007, rural children aged 0 to 5 make up two thirds of the entire children in China. Therefore, to ensure the enrollment rate in rural undeveloped areas, the number of kindergarten in rural 
areas should be no less than two thirds of the total number of Chinese kindergartens (Luo and Chu 2008).

However, according to the data, the proportion of rural kindergartens only accounted for $47.52 \%$ of total number of kindergartens, which was much lower than the theoretical value and led to a predicament of 'no kindergarten for rural children.' Therefore, the Guiding Opinions failed to achieve the target.

According to this theory, to reach the kindergarten 1-year gross enrollment rate of 95\% proposed by Chinese Mid- and Long-term Education Reform and Development Plan (2010-2020), rural area is vital. The groundwork for improving the access of ECE in rural area is establishing more kindergartens, which would provide more educational opportunities for rural children. However, from 2006 to 2010, the number of kindergarten in rural China had been less than half of the number in national level. In 2010, the proportion of rural kindergarten was less than the proportion of urban kindergarten by $4.82 \%$, which directly contributed to an urban-rural gap of $35.49 \%$ in kindergarten gross enrollment rate. The Chinese government has realized this; in the recent policy documents, it proposed 'vigorously develop public kindergartens' (The State Council of the People's Republic of China 2010a) as well as 'expand rural early childhood education resources by multiple ways, reconstruct and add kindergartens' and 'actively support the development of public-oriented, private kindergartens with affordable fees, and public-oriented kindergarten' (The State Council of the People's Republic of China 2010b) in the Plan and the Opinion, respectively.

Under the guidance of these two documents, the Chinese government carried out the document Ministry of Finance, Ministry of Education: The Notice on Increasing Financial Investment to Support the Development of Early Childhood Education. It required the local government to convert idle rural schools and surplus public resources into kindergartens, build kindergartens affiliated to local rural primary schools, and to open up multiple approaches to establish rural kindergartens. According to preliminary statistics, the number of rural kindergarten restructured from surplus primary school resources and other public resources has reached 3.4 million, and the number of affiliated kindergarten is more than 4.6 million (Ministry of Education of the People's Republic of China 2014a).

Besides, based on local the Three-Year Action Plan, local authorities have set a series of goals on establishing rural kindergartens. The eastern developed regions proposed to establish town center kindergartens in $80 \%$ to $100 \%$ of the townships to promote the development of rural kindergartens; the figures of western undeveloped regions were $50 \%$ to $100 \%$. In addition, every province has also developed specific measures in accordance with its local realities. For instance, in Anhui province, the establishment of public kindergartens in rural area have been integrated into the service system for left-behind children, etc. (Tian and Zhou 2012).

\section{Improvement of teachers' qualification and enhancement of the quality of rural ECE}

Teachers are the most significant resource of education. The quality of teachers largely determines the quality of education. Furthermore, improving educational equity mainly depends on qualified teachers and the high quality education children can receive from competent teachers (OECD 2011b). Therefore, strengthening rural kindergarten teachers' qualification is the prerequisite of promoting the equity and enhancing the quality of Chinese ECE. Study shows that the most effective way to improve educational equity is 
to provide pre-service and in-service teacher education (Musset 2009). Thus, improving the qualification of rural kindergarten teachers is closely connected with Chinese teacher education policies and is of essential importance to the balanced development of Chinese ECE.

However, in China, both the quantity and quality of rural kindergarten teachers are much lower than their counterparts in urban areas. Based on Chinese national realities, the State Council proposed increase efforts to train kindergarten teachers in rural areas and expand the enrollment scale of students who participate in Free Teacher Education Program and major in early childhood education'. In 2011, Ministry of Finance, Ministry of Education: The Notice on Increasing Financial Investment to Support the Development of Early Childhood Education clearly stated 'Rural kindergarten teachers' training in central and western areas should be integrated into "National Teachers Training Program".' In the following year, the State Council emphasized to 'develop school and kindergarten teachers training, especially in rural areas' in State Council: Opinion on Strengthening the Construction of Teachers' Team (The State Council of the People's Republic of China 2012). According to the guidance of these documents, the Ministry of Education and governments at different levels have taken a range of measures to increase the number of kindergarten teachers and enhance the teachers training in rural areas.

The 'Free Teacher Education Program' as well as Mobile Rural Early Childhood Education-Supporting Sites Project is a typical project to supplement the rural kindergarten teacher resources initiated by the Chinese government. Free Teacher Education Program is a kind of university-level teacher education scheme free of charge, which is conducted in six state-sponsored universities. Every student involved in this program enjoys reduction of all expenses and receives a subsidy on a monthly basis during the whole study period, but the student has to return to the place of origin and engages in education for a decade after the graduation. The essence of this program is to attract qualified teachers to serve in rural area through strong economic incentives (Wang and Gao 2013). In addition, the Ministry of Finance and the Ministry of Education had jointly launched the Mobile Rural Early Childhood Education-Supporting Sites Project. This project aims at providing various and flexible mobile guidance for children and parents in remote areas by recruiting volunteers from rural kindergarten teachers, college graduates, or graduates of kindergarten teacher training school. This project relies on available rural kindergartens and other available resources. By 2013, this project has set up over 1,500 education-supporting sites and recruited more than 4,000 volunteers. Overall, 13 provinces and approximately 40,000 children has benefited from this project (Ministry of Education of the People's Republic of China 2014a).

The National Kindergarten Teacher Training Project is a major in-service training program established for kindergarten teachers in rural areas. This project was jointly launched by the Ministry of Education and Ministry of Finance in 2011, aiming at improving the level of teaching and professional competence of rural kindergarten teachers. The main beneficiaries of this project are rural public and public-oriented private kindergarten teachers, teachers transferred from primary schools, and head teachers. Professional Standards for Kindergarten Teachers provide the basic contents and standard for the training, which includes three dimensions (professional philosophy and ethics, professional knowledge, and professional skills) with detailed areas and specific requirements (Li 2013). The training involves not only traditional forms like lectures and seminars but also creative teaching modes, such as 'participatory training' (a training mode in which trainees are involved into 
the process of learning, teaching, and discussing) and 'shadow teachers' (a training mode conducted in kindergartens; in this mode, a trainee follows the lead of a qualified kindergarten teacher - just like a 'shadow', observing the tutor's teaching methods and learning from the tutor's experience). In the overall level, kindergarten teachers consider that the National Kindergarten Teacher Training Project is a powerful measure to develop rural ECE (Huang 2012). Regrettably, government at different levels has not yet explicitly associated in-service training for rural kindergarten teachers with their performance appraisal. That is to say, kindergarten teachers who have completed 'National Kindergarten Teacher Training' can hardly be rewarded with salary increase and promotion, which negatively affected the outcome of the project. So far, this project has attracted 1.1 billion RMB as the funding from the central government and has trained 296,000 rural kindergarten teachers (Ministry of Education of the People's Republic of China 2014a).

\section{Establishment and development of ECE funding system to support disadvantaged children}

Difference in socioeconomic status is one of the factors leading to educational inequity. Families in different socioeconomic status have different financial abilities to pay for the costs of ECE service. Therefore, improving the affordability is vital to improve the kindergarten enrollment rate for disadvantaged families (Levin 2003). Many countries around the world support disadvantaged children to access to high quality ECE by ECE funding project. 'Head Start' in America and 'Promoting ECE Participation Project' in New Zealand (Ministry of Education of New Zealand 2013) are a few successful examples.

To support the disadvantaged children and to promote the equity of Chinese ECE, the Chinese government proposed 'improve reasonable cost-sharing mechanisms and provide funding to help children who are living in poverty to go to kindergarten' and 'establish ECE funding system, subsidize children from low socioeconomic status families, orphans, and children with special needs, to enable them to receive public-oriented ECE' in Chinese Midand Long-term Education Reform and Development Plan (2010-2020) and State Council: Opinion Concerning Current Development of Early Childhood Education. In 2011, 'Early Childhood Education Funding System' was established, marked by the document Ministry of Finance, Ministry of Education: The Notice on Increasing Financial Investment to Support the Development of Early Childhood Education. It proposed that 'local governments take actions firstly, the central government subsidizing later'. This system aims to support children from poor families and rural children living in poverty. This system is mainly established by the local government based on local circumstance and the central government provides subsidies to every province according to the local reality.

Nowadays, local governments in China have generally established their own ECE funding system. Orphans, disabled children, and children from poor families are all included in the system in every province. Additionally, 'revolutionary martyrs' children' (children whose parents died for the wellbeing of the society), ethnic minority children, and migrant workers' children can also benefited from the funding system in Zhejiang, Shandong, and Liaoning Provinces which have expanded the funding beneficiaries. According to the financial conditions of every province, there are differences in funding standards. For example, the minimum funding standard is 400RMB per child per year in Henan Province, while the highest funding standard is 2,400RMB per child per year 
in Liaoning Province. In some other provinces like Shandong, Jiangsu, Inner Mongolia, and Shanghai, subsidies are distributed in different scales according to different children's needs. In terms of the forms of funding, the main approach is subsidy which includes 'vouchers' and cash grants, while supplementary measures include reduction of fees for care and education. For instance, Hainan Province reduces the cost of disabled children's care and education. Meanwhile, kindergartens should contribute 3\% of their revenues to subsidize the costs of disadvantaged children's care and education (Sun 2012). By 2013, local governments in China have established ECE funding system and have invested 3.6 billion RMB, benefiting over 4 million children (Ministry of Education of the People's Republic of China 2014a).

\section{Strengthened supervision and evaluation system to ensure the effective development of rural ECE}

People's Republic of China Education Law clearly provides that educational supervision is a basic system of Chinese education. Scientific educational supervision and evaluation system is a significant factor to ensure the implementation of education policy and the promotion of education quality. Among the major projects to promote equity of ECE around the world, supervision and evaluation system are both integral parts of them. 'The National Evaluation of "Sure Start"' was established at the beginning of Sure Start, targeting to conduct comprehensive assessments to the implementation of Sure Start and propose modifications and strategies to improve the project accordingly (NESS 2014). As a developing country, India also established an evaluation system of 'Integrated Child Development Services' and made the policy decision the assessments of the performance (Kapil 2002).

However, rural ECE in China has long suffered from the lack of effective supervision, which exacerbates the urban-rural gap. In other words, a strong supervision and evaluation system is essential to ensure the effective promotion of rural ECE development and Chinese ECE equity. Therefore, the Chinese government proposed to 'establish kindergartens license and supervision system, strengthen the management of ECE' and 'educational departments should strengthen the supervision and management as well as scientific guidance of ECE' in Chinese Mid- and Long-term Education Reform and Development Plan (2010-2020) and State Council: Opinion Concerning Current Development of Early Childhood Education. To implement the guidance of the Plan, the Ministry of Education distributed the Interim Measures on Supervision and Evaluation of Early Childhood Education in 2010, presenting a detailed description of the content, form, and standards of the supervision and evaluation. According to the Interim Measures, the supervision and evaluation of Early Childhood Education Three-Year Action Plan is carried out by the National Education Supervision Group. The Supervision Group assesses local government from six aspects, including responsibility implementation, funding, education resources expanding, kindergarten teachers' training, ECE administration, and development level. In terms of the process of evaluation, local governments should establish evaluation systems firstly and inspect its subordinate districts accordingly. Then, they need to fill in the documents and report to the National Education Supervision Group. National Education Supervision Group should inspect local governments periodically and compile annual education supervision report based on information collected from the local governments. 
According to the Interim Measures and local realities, the local governments in China have generally set up specific supervision and evaluation plans for ECE in rural areas. For instance, Liaoning Province has established the mechanism that local administrator should be responsible for the performance of local kindergartens and the results of evaluation should be announced to the public. Tieling, a city of Liaoning Province, put rural ECE development as an important item of the main government officials' assessment at all levels ( $\mathrm{Li}$ and Han 2010). The Department of Education of Shandong Province stipulates that the supervision at all levels should concentrate on factors including ECE investments, the quality of education and care, and teachers' salary and benefits (Yang et al. 2011).

Under the guidance of Chinese Mid- and Long-term Education Reform and Development Plan (2010-2020) and State Council: Opinion Concerning Current Development of Early Childhood Education, the first Early Childhood Education Three-Year Action Plan has successfully completed by 2013. ECE in rural China has made significant progress. In terms of educational opportunities, by 2013, over 80,000 kindergartens have been established through multiple approaches and more than 1,500 education-supporting sites have been set up. They all provide more educational opportunities for children in rural China. As for teacher quality, the proportion of rural kindergarten teachers graduated from teacher training school or above accounted for $46.42 \%$ in 2012 , 5\% higher than the figure in 2010 . The urban and rural gap has decreased by $2.28 \%$. Besides, during the period of 2010 to 2012, the proportion of ECE expenditure rose from $1.7 \%$ to $3.4 \%$ of the national education expenditure.

According to the statistics above, the efforts of the Chinese government to promote rural ECE in recent years are impressive and effective. However, in comparison with the developed countries, there are still problems existing in rural China, such as low enrollment rate in scattered populated areas. The rural kindergarten conditions are still undesirable, and rural kindergarten teachers are very unstable. It still needs some time to close the gap between urban and rural ECE development.

\section{The challenges and prospects of rural ECE in China}

In the Fifth National Conference on Women and Children in 2011, Chinese Prime Minister Wen Jiabao said, 'Children should be the first to enjoy the social welfare, the last to suffer from a disaster' (Wen 2011). By the end of 2013, China has successfully completed the first phase of the Early Childhood Education Three-Year Action Plan, and the kindergarten crunch has been alleviated preliminarily (Ministry of Education of the People's Republic of China 2014b). In the past 3 years, the Chinese government attached great importance to equity of ECE and distributed several policies and measures to combat the problems. The government has narrowed the urban-rural differences and has increased rural public-oriented ECE resources rapidly. Moreover, the financial investment for rural areas has increased substantially, and rural kindergarten teachers' qualification has been enhanced steadily. Overall, rural kindergartens in China have witnessed considerate improvement. However, Chinese rural ECE development is still affected by the late start and the weak foundation. Nowadays, it remains to be the weakest component of public ECE service system, with several problems to be solved. 
The severe shortage of rural public-oriented ECE resources

In 2013, the national 3-year gross ECE enrollment rate reached $67.5 \%$, rising by $10.9 \%$ compared with 2010. But in the mid-western rural areas, especially concentrated destitute areas, ethnic minority areas, and concentrated areas of left-behind children, the overall enrollment rate is still low. It means that the majority of rural children who accounts for two thirds of the total number of children cannot enjoy quality ECE. Also, both urban and rural ECE in China are confronted with the uneven distribution of educational resources. Rural kindergartens are exceptionally constrained by the scarcity of resources and finance in rural areas (Ministry of Education of the People's Republic of China 2014a). As a result, when dealing with ECE equity issues, China needs to consider the overall shortage of ECE resources in remote and poor areas. The government should continue to expand ECE resources, especially public-oriented resources to $\mathrm{s}$ rural areas, to solve the issue of kindergarten crunch and to promote the spread of ECE in rural areas. Furthermore, The Outline for Chinese Children's Development (2010-2020) specified that the government should 'prioritize the development of rural ECE, establish at least one central kindergarten in each township, build independent kindergartens for big villages, with branch kindergartens or joint kindergartens for small villages, provide flexible ECE services for scattered-populated regions, equip touring instructors, and gradually improve the ECE network in county, township and village levels' (The State Council of the People's Republic of China 2011). In addition, in order to promote the balance of allocation of ECE resources in rural areas, National Plan for Child Development in Poor Areas (2014-2020) is expected to be promulgated by the State Council in 2014. Then the government will provide the support and intervention for aged 0 to 15 in disadvantaged areas (Ministry of Education of the People's Republic of China 2014c).

The undesirable rural kindergarten condition and the urgency to establish cost-sharing and operation- supporting system

With the introduction of The Interim Measures of Tuition Administration for Kindergartens, The Kindergarten Work Regulation and The Kindergarten Construction Standards, the management system to supervise kindergarten's tuition, daily operation, building construction, teaching facilities, and toys has been established in rural areas, but a mechanism of extensive cost-sharing and operation support is still needed. Most of the rural kindergarten teachers' salaries and the daily operations of kindergartens rely mainly on tuition fees. For one thing, the sources of funding are limited and parents are suffering from heavy financial burdens. For another thing, the basic kindergarten conditions can hardly be guaranteed, which results in the 'oversized classes'. According to The Work Points of Ministry of Education in 2014, China will further improve the level of support and management of educational funding to supervise the financial growth and widen the channel of funding sources. In terms of the specific cost-sharing bodies in rural ECE, the government should take a clear responsibility for providing funding support. The government will also pay the largest share of ECE service and individual families will only contribute a small fee (Chen 2012). Meanwhile, the central government will formulate policies to encourage social entities to run or donate kindergartens. Moreover, the investment responsibility for ECE of different levels of government is defined (Yang et al. 2012). In this way, the government can become the pillar of development strategy for early 
childhood education and the mechanism to ensure the support by public finances' (Pang and Xia 2013). In addition, local governments should develop rural children's funding standard and finance allocation criteria based on empirical studies. The ECE funding system should also be established to provide aids to children in poverty orphans and children with special needs so that they can receive quality ECE. Moreover, the government should strengthen the investment and funding for remote and poor areas and ethnic minority areas (The State Council of the People's Republic of China 2010b).

The low rural kindergarten teachers' qualification and professionalism and the importance of improving teacher training system and protecting teachers' rights

By 2012, the number of kindergarten teachers in urban areas is 5.44 times more than that in rural areas. The number of kindergarten teachers with academic qualifications above associate bachelor in urban areas is 8.04 times higher than that in rural areas. According to the data of 2013, the disparity is even expected to increase. Therefore, rural kindergarten teachers' social status and welfare are relatively low, which has negative effects on the job stability of rural kindergarten teachers. In addition, due to the defective mechanism to attract talented teachers, rural areas can hardly retain highly qualified kindergarten teachers, which hinders the improvement of the quality of rural kindergartens. Therefore, the key to sustainable development of rural kindergartens is to equip and train teachers with a well-designed mechanism. To this end, the Ministry of Education prepares 'to build a comprehensive standard for teachers, to promulgate kindergarten head teachers' professional standards', 'promote the reform of the form of kindergarten teachers' training', and 'start the crucial plan of construction of kindergarten teachers' (Ministry of Education of the People's Republic of China 2014c). Whether or not the above goals can be realized depends on rural teachers' training and welfare. Hence, the status and salary of rural teachers should be guaranteed in accordance with $>$ the law. Finally, in order to attract the truly talented teachers, 'For one thing, (the government should) supplement rural teachers with "fresh blood" through the employment mechanism via "Special Post Plan" (a national plan to recruit highly educated professionals to teach in rural kindergartens)'; 'For another, effective supervision and evaluation system should be established to enhance the effects of urban-rural teacher exchange' (Ministry of Education of the People's Republic of China 2014d).

\section{The need to improve quality supervision and evaluation system}

'The quality supervision of children's education and care aims at promoting educational equity, implementing well-rounded education, and improving educational quality' (Dong 2007). The quality of current supervision system of children's education and care needs to improve. In many rural areas, local kindergartens do not perform according to the law and government policy. In some rural regions, the kindergartens become 'primary schoolized', the kindergartens focus on rote learning, passing the knowledge of primary school to young children and neglect their interest and overall development. Due to the lack of appropriate system of supervision and evaluation, the quality of education and care in rural kindergartens can hardly be assured, which undoubtedly exacerbates the problem of 'inequitable development of children between urban and rural areas and the low level of children's overall development in poverty-stricken areas' 
(The State Council of the People's Republic of China 2011). In order to promote the integration of urban-rural ECE development, it has become an international consensus that early intervention is necessary (OECD 2012). To improve rural kindergarten conditions and the quality of ECE, enhancing the evaluation system is essential. The government should strengthen the guide of rural ECE, establish the regional and local kindergartens' institutions for teaching and research, and integrate quality improvement of rural ECE into the supervision and evaluation system of local governments' performance.

\section{Conclusions}

Chinese per capita GDP ranks almost the ninetieth in the world. However, according to United Nations standards, there are still 128 million people living in poverty, most who are from rural areas (Liu 2013). In seeking the welfare of preschool children, the biggest challenge that China is confronted with is to promote the development of rural ECE effectively. The Chinese government has introduced a series of policies of 'wide intervention, comprehensive support' to promote the equitable development of rural ECE, 'to provide better education for the next generation, and make every child have an equal opportunity of development' (Li, 2014). Based on the heritage of the 'equity' in the first Early Childhood Education Three-Year Action Plan, the second Early Childhood Education Three-Year Action Plan will continue to increase the investment and preferential policies in rural areas to 'continue to fight against poverty, and never let poverty carry on from generation to generation' (Li 2014).

\section{Notes}

1. Table 3: In this study, 3 years ECE gross enrollment rate $=($ The total number of children in kindergartens $\div$ The total population of 3 to 6 years old children) $\times 100 \%$, 1 year ECE gross enrollment rate $=($ Total number of 5 to 6 -year-old children in kindergartens $\div$ The total population 5 to 6 years old children) $\times 100 \%$. Among them, the number of children in kindergartens is from China Education Statistical Yearbook, 2006 to 2011; the population data divided by age from the China Population and Employment Statistical Yearbook, 2006 to 2011.

2. Table 5: (a) For the urban-rural distribution of teachers' qualification, 'above associate bachelor' means teachers with degrees higher than associate bachelor degree, including associate bachelor degree, undergraduate degree, and graduate degree. (b) The proportion of urban kindergarten teachers above associate bachelor $=$ The number of urban kindergarten teachers above associate bachelor $\div$ The total number of urban kindergarten teachers $\times 100 \%$; The proportion of rural kindergarten teachers above associate bachelor $=$ The number of rural kindergarten teachers above associate bachelor $\div$ The total number of rural kindergarten teachers $\times 100 \%$.

3. Table 6: (a) The specific routes to achieve different professional titles are listed as follows. Senior secondary title: applicants should either work more than 1 year after receiving a $\mathrm{PhD}$ or work with a senior primary title in at least 5 years after receiving a bachelor's degree (BD) or a master's degree (MD) or get an associate's degree engage in ECE for at least 20 years and work with a senior primary title for at least 5 years. Senior primary title: applicants should either hold a MD or a BD 
and complete a 1-year internship or work with an associate's degree and a first grade primary title for at least 5 years. First grade primary title: applicants get an associate degree with a 1-year internship or graduate from secondary normal school and work with a second grade primary title in at least 3 years. Second grade primary title: graduated from secondary normal school and completed a 1-year internship. Third grade primary title: newly recruited full-time teachers in the kindergartens (especially public kindergartens) recorded by relevant education department.

(b) The proportion of urban kindergarten teachers with a certain title $=$ The number of urban kindergarten teachers with a certain title $\div$ The total number of kindergarten teachers with a certain title $\times 100 \%$; The proportion of rural kindergarten teachers with a certain title $=$ The number of rural kindergarten teachers with a certain title $\div$ The total number of kindergarten teachers with a certain title $\times 100 \%$. Among them, the total number of kindergarten teachers with a certain title $=$ The number of urban kindergarten teachers with a certain title + The number of rural kindergarten teachers with a certain title.

Competing interests

The authors declare that they have no competing interests.

\section{Acknowledgements}

This work was supported by the Chinese Ministry of Education under Grant for the Project of Humanities and Social Sciences (Project No.11YJC880028) \& "the Fundamental Research Funds for the Central Universities".

\section{Author details}

${ }^{1}$ Faculty of Education, Beijing Normal University, No. 19, XinJieKouWai St., HaiDian District, Beijing, China. ${ }^{2}$ Moray House School of Education, University of Edinburgh, Thomson's Land 1.09, Holyrood Road, Edinburgh EH8 8AQ, UK.

Received: 2 October 2014 Accepted: 14 April 2015

Published online: 19 May 2015

\section{References}

Aboud, FE, \& Hossain, K. (2011). The impact of pre-primary school on primary school achievement in Bangladesh. Early Childhood Research Quarterly, 26(2), 237-246.

Agrawal, T. (2014). Educational inequality in rural and urban India. Int J Educ Dev, 34, 11-19.

Berlinski, S, Galiani, S, \& Gertler, P. (2009). The effect of pre-primary education on primary school performance. J Public Econ, 93(1), 219-234.

Brock, A. (2009). Moving mountains stone by stone: reforming rural education in China. Int J Educ Dev, 29(5), 454-462.

Castelli, L, Ragazzi, S, \& Crescentini, A. (2012). Equity in education: a general overview. Procedia - Social and Behavioral Sciences, 69, 2243-2250.

Chapman, B, \& Lounkaew, K. (2013). Introduction to the special issue on economic research for education policy. Econ Educ Rev, 37, 200-203.

Chen, L. (2012). Literature review of early childhood education cost-sharing system. Educational Development, 2, 17-21. In Chinese.

Dong, Q. (2007). Build basic education quality monitoring system with Chinese characteristics. People's Education, Z2, 13-14. In Chinese.

Hannum, E, Liu, JH, \& Frongillo, EA. (2014). Poverty, food insecurity and nutritional deprivation in rural China: implications for children's literacy achievement. Int J Educ Dev, 34, 90-97.

Heckman, J. (2011). The economics of inequality: the value of early childhood education. Am Educ, 35(1), 31-35.

Hong, X, \& Luo, L. (2012). Analysis of differences in preschool education development in urban and rural China from the perspective of education equity. Educ Stud, 8(5), 73-81. In Chinese.

Hong, X, \& Pang, L. (2009). On the protection system of early childhood education and the responsibility of government. Studies in Preschool Education, 1, 3-6. In Chinese.

Hu, BY, \& Roberts, SK. (2013). A qualitative study of the current transformation to rural village early childhood in China: Retrospect and prospect. Int J Educ Dev, 34, 316-324.

Huang, W. (2012). How to make "National Kindergarten Teacher Training Project" more splendid. http:// edu.people.com.cn/n/2012/1022/c1053-19342335-1.html. Accessed 10 March 2014.

Kapil, U. (2002). Integrated Child Development Services (ICDS) scheme: a program for holistic development of children in India. Indian J Pediatr, 69(7), 597-601.

Levin, B. (2003). Approaches to equity in policy for lifelong learning. Paper commissioned by the Education and Training Policy Division, OECD, for the Equity in Education Thematic Review. OECD. http://www.oecd.org/edu/ innovation-education/38692676.pdf. Accessed 6 March 2014.

Li, F. (2013). There are 4 relationships should be cleared in 'National Kindergarten Teacher Training Project'. Education Exploration, 9, 149-150. In Chinese. 
Li, K. (2014). Government work report-in the twelfth session of the National People's Congress second conference on March 5, 2014. http://www.moe.gov.cn/publicfiles/business/htmlfiles/moe/s7904/201403/164925.html. Accessed 8 March 2014. In Chinese.

$\mathrm{Li}, \mathrm{L}$, \& Han, X. (2010). Taking government-dominant strategy and vulnerable assistance principle as the guide to promote early childhood education development: successful experiences from Liaoning Province. Studies in Preschool Education, 8, 3-9. In Chinese.

Liu, ZL. (2010). The emphasis should be put on the rural preschool education. Studies in Preschool Education, 12, 3-6. In Chinese.

Lounkaew, K. (2013). Explaining urban-rural differences in educational achievement in Thailand: evidence from PISA literacy data. Econ Educ Rev, 37, 213-225.

Luo, G, \& Chu, Z. (2008). Different starting line: the analysis of uneven development of early childhood education in China. Shanghai Research on Education, 9, 12-14. In Chinese.

Ministry of Education of New Zealand. (2013). ECE Participation Programme. http://www.lead.ece.govt.nz/ ProgrammesAndlnitiatives/ECEParticipationProgramme.aspx. Accessed 20 March 2015.

Ministry of Education of the People's Republic of China. (2014a). Early Childhood Education Three-Year Action Plan has completed successfully. http://www.moe.gov.cn/publicfiles/business/htmlfiles/moe/s5147/201402/164690.html. Accessed 7 March 2014.

Ministry of Education of the People's Republic of China. (2014b). The introduction materials of Early Childhood Education Three-Year Action Plan press conference. http://www.moe.gov.cn/publicfiles/business/htmlfiles/moe/ s7881/201402/164609.html. Accessed 7 March 2014

Ministry of Education of the People's Republic of China. (2014c). The work points of ministry of education in 2014. http://www.moe.gov.cn/publicfiles/business/htmlfiles/moe/s5987/201401/163169.html. Accessed 7 March 2014

Ministry of Education of the People's Republic of China. (2014d). Building a high-quality teaching staff in rural areas. http://www.moe.gov.cn/publicfiles/business/htmlfiles/moe/s7907/201403/164941.html. Accessed 8 March 2014

Musset, P. (2009). Initial teacher education and continuing training policies in a comparative perspective: current practices in OECD countries and a literature review on potential effects. OECD Education Working Papers No. 48. OECD. http://dx.doi.org/10.1787/5kmbphh7s47h-en. Accessed 7 March 2014.

National Bureau of Statistics of the People's Republic of China. (2010). The Provisions on delimiting town or city by statistic (trial). http://nhs.saic.gov.cn/wcms2/actsociety/normal/html/1219.htm. Accessed 13 December 2014.

OECD. (2006). Annex E. Country profiles: an overview of ECEC systems in the participating countries. In Starting strong II: early childhood education and care (pp. 349). http://www.oecd-ilibrary.org/content/book/9789264035461-en. Accessed 20 March 2015.

OECD. (2008). Policy brief: ten steps to equity in education (pp. 2). Paris: OECD. http://www.oecd.org/education/school/ 39989494.pdf. Accessed 17 January 2014.

OECD. (2011a). Divided we stand: Why inequality keeps rising. Paris: OECD.

OECD. (2011b). Teachers matter: attracting, developing and retaining effective teachers. Paris: OECD.

OECD. (2012). Starting Strong III: A quality toolbox for early childhood education and care. Paris: OECD. http:// dx.doi.org/10.1787/9789264123564-en. Accessed 10 April 2015.

OECD. (2013). How do early childhood education and care (ECEC) policies, systems and quality vary across OECD countries. http://www.oecd-ilibrary.org/docserver/download/

5k49czkz4bq2.pdf?expires=1428717345\&id=id\&accname=guest\&checksum=35E26D9366A35A12EE9A299BFA82EFBE. Accessed 10 April 2015.

OECD. (2014). Education at a Glance 2014: OECD indicators. Paris: OECD. http://dx.doi.org/10.1787/eag-2014-en. Accessed 29 October 2014

Pang, L, \& Xia, J. (2013). International early childhood education developmental stratagem: universalization, equity and high quality. Education Studies, 3, 29-55. In Chinese.

Sun, M. (2012). Policies of early childhood education support to the socially disadvantaged children: reform and enlightenment. Schooling Studies, 9(6), 28-38. In Chinese.

The National Evaluation of Sure Start website. http://www.ness.bbk.ac.uk/. Accessed 3 March 2014

The State Council of the People's Republic of China. (1995). Decision concerning the acceleration of advancement of science and technology.http://www.most.gov.cn/ztzl/qgkjdh/qgkjdhbjzl/qgkjdhbjkjdh/bjzl-dh-9502.htm. Accessed 19 March 2015.

The State Council of the People's Republic of China. (2003). Guiding opinions on the reform and development of early childhood education. http://www.moe.edu.cn/publicfiles/business/htmlfiles/moe/moe_13/200102/189.html. Accessed 1 March 2014.

The State Council of the People's Republic of China. (2010a). Chinese mid- and long-term education reform and development plan (2010-2020). http://www.moe.edu.cn/publicfiles/business/htmlfiles/moe/moe_838/201008/ 93704.html. Accessed 7 March 2014.

The State Council of the People's Republic of China. (2010b). State Council: opinion concerning current development of early childhood education. http://www.gov.cn/zwgk/2010-11/24/content 1752377.htm. Accessed 7 March 2014

The State Council of the People's Republic of China. (2011). Outline for Chinese children's development (2010-2020). http://www.gov.cn/gongbao/content/2011/content_1927200.htm. Accessed 1 March 2014.

The State Council of the People's Republic of China. (2012). State Council: opinion on strengthening the construction of teachers' team. http://www.moe.gov.cn/publicfiles/business/htmlfiles/moe/moe_1778/201209/141772.html. Accessed 7 March 2014.

Tian, J, \& Zhou, F. (2012). Existing foundation and development orientation of preschool education. Preschool Education 8, 30-35. In Chinese.

UNESCO. (2008). Highlights of the EFA Report 2009. Overcoming inequality: why governance matters (pp. 1). www.unesco.org/publishing. http://unesdoc.unesco.org/images/0017/001776/177683e.pdf. Accessed 20 March 2015

Wang, D, \& Gao, M. (2013). Educational equality or social mobility: the value conflict between preservice teachers and the Free Teacher Education Program in China. Teach Teach Educ, 32, 66-74. 
Wen, J. (2011). The speech in The Fifth National Conference on Women and Children. http://www.moe.gov.cn/ publicfiles/business/htmlfiles/moe/moe_176/201111/127197.html. Accessed 1 March 2014.

Yang, D, Li, H, \& Dai, M. (2011). Strengthening the leading responsibilities of the government to promote the development of rural preschool education in Shandong Province. Studies in Preschool Education, 11, 17-22. In Chinese.

Yang, H, Zhang, Z, \& Liu, S. (2012). The characteristics, problems and policy recommendations of rural early childhood education funding security system in China. Educational Development, 3, 17-21. In Chinese.

Young, ME. (2002). Introduction and overview. In ME Young (Ed.), From Early Child Development to Human Development: Investing in Our Children's Future (p. 10). Washington, DC: The World Bank.

Zhang, C, \& Yu, ZF. (2009). Predicament and countermeasure of the pre-school education cap between urban and rural areas. Research in Educational Development, 24, 32-36. In Chinese.

\section{Submit your manuscript to a SpringerOpen ${ }^{\circ}$ journal and benefit from:}

- Convenient online submission

- Rigorous peer review

- Immediate publication on acceptance

- Open access: articles freely available online

- High visibility within the field

- Retaining the copyright to your article

Submit your next manuscript at $\boldsymbol{\sim}$ springeropen.com 